\title{
Do Environmental Regulations Affect the Location Decisions of Multinational Gold Mining Firms?
}

\author{
Lise Tole* \& Gary Koop \\ Department of Economics, University of Strathclyde
}

August 12, 2008

\begin{abstract}
This paper empirically analyzes the location decisions of the world's major gold mining firms using a data set of political, economic, regulatory, infrastructural and investment risk variables observed for a large number of gold producing countries since 1975. The aim of the study is to determine the significance of environmental stringency in forming location decisions while controlling for other potentially important variables that may affect such decisions. Using both a conditional and a mixed logit regression approach, the study finds consistently strong country location preferences among multinational gold mining firms. These preferences paint a picture of an industry attracted to countries that are close to their head office, provide a business environment characterized by low levels of financial risk and high levels of political stability and predictability in mining operations. While mining firms also appear to be attracted to countries that have a clean environment is less strong and uniformly robust. This preference for a clean environment may itself be reflective of the strong desire to go to countries that are efficiently run, provide clear rules and regulations, and are secure and predictable in their operations. Moreover, while they prefer to go to countries with low levels of corruption, this characteristic seems less important than the desire for security, transparency and stability in government and operations. Taken together, these preferences for a clean, well-run countries may reflect the adoption by mining firms of a deliberate strategy intended to minimize the risks to their hugely expensive and immobile investments.
\end{abstract}

Acknowledgements: We would like to thank Andreas Tegen for his expert advice on a number of gold mining issues and Dimitris Korobolis for his help on data preparation. This study was generously supported by a grant from the British Academy (Grant \#).

*Corresponding author: Lise Tole, Department of Economics, University of Strathclyde, Glasgow, U.K., G4 OGE, lise.Tole@strath.ac.uk 


\section{Introduction}

The global gold mining industry provides an excellent opportunity in which to analyze the impacts of differential environmental standards on firm location decisions. First, investment in this industry has expanded rapidly in recent decades due to privatization, deregulation and liberalization initiatives which many governments have pursued since the 1980s. Foreign direct investment flows in the mining sector have accelerated rapidly in the poorer countries of the world, buoyed by high world prices for precious metals.

Accelerating opportunities for foreign investment have also brought with them increasing public concern about the environmental impacts of mining operations worldwide. Concern has focused, in particular, on the implications of differential environmental standards on foreign direct investment in the mining industry. There is increasing concern that international mining companies may be motivated to set up operations in poor countries because environmental regulations are weaker and compliance less strictly monitored. Governments, eager to attract foreign investment, may themselves weaken - or simply fail to strengthen - existing regulations and sanctions, in order to attract much needed foreign investment. In the mining industry, the huge environmental impacts associated with mining operations makes this a very real concern. The scale and impacts of mining operations impose huge environmental liabilities, much greater than those faced by other industries. Hence a desire to avoid such costs could be a significant component of the multinational mining firm's decision to seek out countries with weaker environmental legislation and limited institutional and technical capacity to regulate and monitor their polluting activities.

However, it is also possible that the multinational mining firm views migration to poor countries as ultimately a bad thing for both their profit margin and their public image. Locating in such places, which also tend to be both economically and politically unstable and undemocratic, may be deemed to be too risky for their public image. Once largely shielded from public scrutiny, mining firms have had to adjust to an increasingly globalized world of instant media coverage, which has fueled public concern over the environmental impacts of mining and raised expectations of corporate performance and responsibility in this industry (Ramy 2003). Hence any savings in costs from lax environmental regulations may pale in comparison to the costs incurred by a negative public image, even if firms exceed by a wide margin the environmental standards of their host country. In short, they may decide that their very presence in such countries involves too much hassle to make it worthwhile.

Taking this argument further, the political and business stability that tends to characterize environmentally stringent countries may be a far more important characteristic in a location than the degree of environmental stringency. Once economic and other financial considerations have been weighed, what the firm may desire more than anything else is to be efficiently and fairly treated by its

foreign host, even when it is recognized that environmental policies are likely to change in the future. In this case, a clean environment may reflect the good 
governance that they really crave. Moreover, it is also possible that the costs of environmental stringency are an irrelevant locational concern for mining firms simply because they view the adoption of uniform "best practice" standards around the world as a similar risk minimization strategy designed to inoculate themselves against huge financial losses arising from against future changes in environmental regulations in the host country in years to come.

The extent to which environmental concerns dominate multinational mining firm location choices is a key focus of this paper. It carries out a systematic empirical investigation of environmental regulations in affecting the international siting of gold mining firms. It is the first study to systematically examine firm location decisions in a natural resource industry. It is also one of the few truly global studies on firm location decisions. We measure the location outcomes of multinational gold mining firms as reflected in the birth of new mines since 1975. Most studies in the literature are restricted to either intracountry analyses of firm decisions (largely in the USA, EU or China) or to a few developing countries (e.g. Eskeland \& Harrison 2003). Moreover, our data set allows us to directly observe the multinational decision outcome. The use of disaggregated data at the finest resolution of industry organization enables us to trace the decision outcome of each multinational to its plant rather than inferring location preferences from many, quite heterogeneous plants or from aggregate data at the industry or firm level. The breadth and depth of the data set also allows us to comprehensively control for a range of important country characteristics that may potentially influence choice of mine location.

The study uses both conditional and mixed logit regression approaches to model firm location decisions in the gold mining industry. Our use of mixed logit models is motivated by the well known property that conditional logit models are quite restrictive, requiring an independence of irrelevant alternatives assumption which is likely to be violated here. Mixed logit models relax this assumption and (as shown, e.g., in McFadden and Train, 2000) can approximate well any discrete choice structure. We use Bayesian methods to estimate our models, the advantages of which are outlined in Train (2003).

The remainder of this paper is as follows: Section 2 provides a short motivating description of our study within the context of recent studies on firm location behavior. Section 3 discusses our Bayesian mixed logit modelling ap-

proach. Section 4 provides a comprehensive description of our data set, and Section 5 discusses the results. Section 6 concludes.

\section{Motivation \& Literature Review}

Currently, there is much uncertainty in the empirical literature about whether environmental regulations play any significant role in firm location decisions. This literature contrasts with the majority of theoretical studies, which have consistently demonstrated that a profit-maximizing firm will seek to set up in areas where the production costs of pollution control, environmentally appropriate inputs/outputs, waste disposal charges, etc. are low. (e.g. Baumol \& Oates; 
Copeland \& Taylor 1994). However, some theoretical literature has suggested that environmental regulations do not affect firm location decisions when other factors such as technology adoption and strategic interaction, asymmetric information between countries are considered. Thus, the interplay of these factors will produce different outcomes, e.g. a cleaner environment in the host country, than anticipated by the pollution haven hypothesis (e.g. Wu 1994; Regibeau \& Gallegos 2004).

Most empirical work has concluded that environmental stringency is just one factor in location decisions, and not a very significant one, compared to other country factor endowments such as availability of cheap, skilled labor and quality of infrastructure.(see reviews by Dean 2001 and Jaffe et al. 1995). A related literature indirectly attempts to measure the impact of environmental stringency on firm behavior through changes in inter-industry FDI or trade volumes or wage and capital flows. Empirical evidence from firm location decision studies suggests, at best, a weak role, with later studies inconsistently showing stronger support not found in the earlier studies. Most of this research has been carried out on the USA, exploiting the variation in environmental stringency across states (e.g. Bartik 1989; McConnell \& Schwab 1990; Levinson 1996; 1999; List et al. 2003; Becker and Henderson 2000).

Only a few studies have examined the impact of environmental stringency on firm behavior which also involves a poor country or set of countries. To the best of our knowledge only one study has focused at the plant level, the study by Mani et al. 1996. The authors use a conditional logit analysis to measure the locational choices of manufacturing plants in the 14 largest industrial states in India in 1994. The authors find that agglomeration and spillover effects of other business activity in areas are important factors in the location decisions of firms, as are availability of power and low levels of labour disruption. However, most important for our study, they find that plant location decisions are not affected by the level of environmental enforcement at the state level. Interestingly, plant location is significantly positively related to environmental spending by government.

Of the studies that focus on FDI flows or outputs in poor countries such as production and net exports, the evidence for a role for environmental regulations is much weaker than either plant location or comparable trade/FDI flow studies within the USA. One such study, by Eskeland and Harrison 2003, examines the pattern of foreign investment across industries within Mexico, Venezuela, Morocco and Cote d'Ivoire. They find that abatement costs are not significant determinants of the distribution of foreign investment among manufacturing industries within countries. Foreign ownership appears to be quite significantly associated with lower energy use, the study's proxy for pollution intensity. Similarly, Smarzynska and Wei (2001) evaluate the foreign investment choices of multinational firms in Eastern Europe and the Soviet Union using a firm-level data set on investment projects and pollution output in 24 transition economies. They find weak support at best for the possibility that environmental laxity may might lead to more foreign investment. Support is strongest when environmental regulation is measured by participation in international treaties. In this 
case, investment by pollution-intensive industries as a share of total inward FDI is lower in countries with greater participation. However, the authors caution that support for this association is not robust to various sensitivity checks and the sample size of countries is small, thereby limiting the amount of measurable variation in environmental protection.

Similarly, in an analysis of 2,886 equity joint venture projects during 199396, Dean, Lovely and Wang (2005) measure whether such ventures are affected by environmental levies on water pollution. Using conditional logit and nested logit models, they find that environmental stringency has no impact on location choice. The only exception is joint ventures in highly polluting industries in conjunction with partner firms from Hong Kong, Macau and Taiwan but not from the OECD. Industries from countries in the latter were not attracted by low environmental levies, regardless of their water pollution intensity. Controlling for the fact that industries with the largest pollution abatement costs will be less geographically mobile, Ederington et al. (2005), find a significant effect of pollution abatement costs on imports from developing countries, particularly in pollution-intensive, geographically mobile industries.

The inability of the empirical literature to find strong evidence for a pollution haven hypothesis as predicted by the theoretical literature might be attributable to a number of methodological and data drawbacks. Since this study is concerned with plant location decisions rather than FDI or trade flows, our paper will attempt to address problems in these studies. Specifically, existing plant and firm location studies do not: a) encompass variations in environmental stringency or pollution intensity within a global context due to their restricted geographical focus. Differences in environmental variation may not be large enough to be captured in intracountry studies of firm location and so thus inter-country studies may provide a better indication of firm location preferences from the perspective of environmental stringency. b) Plant location studies are largely cross-sectional, and thus may potentially miss important changes in state or country characteristics that impact on environmental stringency (e.g. changes in the composition and scale of a country's industrial base); c) Studies do not comprehensively control for potentially important non-environmental regulatory and non-economic factors in firm decision-making, such as political stability and corruption level of a country, potential for profit repatriation, internal reinvestment policies, rights of tenure, etc.

\section{Econometric Methods}

The econometric models used in this paper are standard qualitative choice models, but it is worthwhile to briefly define them to motivate the difference between conditional and mixed logit. Such models can be motivated by assuming that mining companies will choose locations where they will maximize their utility (which could just be profit or could be more broadly defined to reflect other firm objectives). In our data set we have 700 new mines opening in 55 countries. To treat each of the 55 countries as a separate "location choice" would lead to a 
model with too many coefficients to be estimated well with a data set of this size. Accordingly (and as we motivate below), we collapse our 55 countries in 11 "country groups". The choice of country groups is largely made on geographical grounds, but we also strive to ensure that countries within a group have very similar values of the explanatory variables and, in Appendix B, we investigate how robust our results are to our definitions of country groups.

Formally, let $U_{i j}$ be the utility that firm $i$ (for $i=1, \ldots, N$ ) gets from opening a mine in country group $j$ and $x_{j}$ be a vector of explanatory variables containing characteristics of country group $j$. If we let:

$$
U_{i j}=\beta_{i}^{\prime} x_{j}+\varepsilon_{i j},
$$

where $\varepsilon_{i j}$ are i.i.d. extreme value random variables and $\beta_{i}$ are i.i.d. $N(b, W)$ random variables then we have the mixed logit model. Train (2003) provides a thorough discussion of the properties of this model. The conditional logit model is a restricted variant of the mixed logit model which imposes that the same coefficients hold for all firms (i.e. $\beta_{i}=\beta$ for $i=1, \ldots, N$ ). The conditional logit model suffers from the well-known independence of irrelevant alternatives assumption. In our study of choice between country groups (or indeed any similar study), this assumption is very likely to be unreasonable. For this reason, although we do present conditional logit results as a familiar benchmark, we place emphasis on the mixed logit model. The mixed logit model is much more flexible than the conditional logit model. Indeed, as shown in McFadden and Train (2000), any discrete choice model based on random utility maximization can be approximated arbitrarily well by a mixed logit model.

With the mixed logit model, there is a different set of coefficients for each firm (i.e. $\beta_{i}$ for $\left.i=1, . ., N\right)$. It would be too much to present empirical results for each of these coefficients. Accordingly, following standard practice, we present the mean of the distribution, $b$, as a measure of the average marginal effect of each explanatory variable on the utility.

Our econometric methods are described in Chapter 12 of Train (2003). This chapter describes how to carry out Bayesian inference (with a noninformative prior) in the mixed logit model as well as motivating why Bayesian methods have desirable properties for this model. ${ }^{1}$

\subsection{Data}

\subsubsection{Dependent Variable}

Our dependent variable is the location decisions of 700 gold mining firms throughout the world using data on year of mine opening (mine births). Although we also have data on mine closings, which could be used a location indicator of the sensitivity to environmental regulations, we use the opening year of new mines instead as our dependent variable. As Levinson (1996) notes, existing plants

\footnotetext{
${ }^{1}$ We use the MATLAB program for Bayesian estimation of the mixed logit model provided on Kenneth Train's website (http://elsa.berkeley.edu/ train/software.html) and we thank him for making this code publicly available.
} 
will have already incurred large sunk costs and thus environmental regulations will have less of an effect on existing mines than the decision to invest in new mines. If profitable, existing mines will likely close only if new environmental regulations incur large costs. New firms will be more sensitive to even minor regulatory changes, ceteris paribus. In addition, unlike manufacturing plants, which can conceivably stay open as long as they remain profitable, all mines have a natural lifespan. Hence a mine closure measure would not be able to distinguish between sensitivity to environmental costs and depleted deposits. Finally, new mines typically do not enjoy "grandfather clause" exemptions from new regulations that often apply to existing mines.

We observe the opening year of each mine from 1975 until 2013. Obviously some mines have yet to open and thus are not operational. However, this subset comprises an extremely small number (25) of mines in our sample. For these firms, the decision to open a mine in a particular country has already been made. Defined in the industry as "pre-operational" these mines are in various stages of construction. However, given our focus is on the location decision rather than the operational mine, it is reasonable to include these few mines in the study. Rather than measuring the actual year of opening for the mines in this small subset, we measure the year in which the decision to set up a mine in a given country was made. This is the year that the mine was given the designation "pre-operational" in company reports, rather than simply being contemplated (i.e. the exploration stage).

Mine births were derived from a proprietary database collected by Raw Metals, a mining industry database used by mining firms and investors (Raw Metals 2007).

\subsection{Country Groupings}

We group mine openings in countries throughout the world. We do this because the number of country locations modelled in our study -55 countries in all - each measured as a single choice would lead to far too many parameters to reasonably estimate our model. In a global study like ours it is desirable to include as many country alternatives as possible (ideally each of our 55 individual countries would be an alternative location). However, with so many countries it is difficult to obtain accurate econometric estimates with so many alternatives and a finite data set. However, given that many countries are quite similar to each other, it is sensible to think that they are very similar in respect to the decision to open a mine. We have carefully chosen our different country groupings with this tradeoff in mind:

a) 11 Country Groupings. In this grouping we reduce our 55 countries to 11 different groups. This is a relatively large number of groups, but not too large to preclude reasonable econometric estimation. It groups countries according to World Bank regional classifications, which we slightly modify. That is, we include the world's biggest and most established gold mining producer countries in their own group rather than in their corresponding World Bank regional group. In other words, Canada and the USA are included alongside South 
Africa, New Zealand and Australia rather than being placed in North America or sub Saharan African regional classifications, respectively.

b) 8 Country Groupings. To try to get even more precise results (and to check if our results are robust) we experimented with further reducing the number of groups of our 55 countries. Our 8 country grouping retains the separate grouping for the big gold mining producing countries of the above, but combines the Latin America and Carribean classifications of the 11 groups into one group. It also combines Southeast Asia, East Asia and Oceania (excluding Australia and New Zealand) into one group.

c) 2 Country Groupings. Rather than divide countries according to their regional classifications, this grouping is a very coarse adaptation of a classification based roughly on the World Bank's income classifications. We collapse their income categories of low, middle, and high as they were in roughly the middle of the sample (1995) into two coarse groupings: Very high income (highly developed) North America and Western Europe, and everbody else (low to middle income) The exception to this grouping is that we place the established producer, South Africa, into the same group as the other established producers, all of which fall into the income category of "highly developed" countries.

From the point of view of the mining executive, our regionally based grouping makes sense. Indeed mining executives are used to making decisions on a regional basis. Most organize their corporation according to regional divisions. Moreover, it is not uncommon for ore bodies of economic importance to straddle one or more countries in geographical proxmity to each other. One example is the Pascua-Lama ore body, which straddles Argentina and Chile. Owned by Canadian multinational, Barrick Gold, it is located in the Frontera District close to the company's Veladero mine. The company also opeates other mines in its South American division, which comprises the countries of Chile, Peru and Argentina. However, even when confined to individual countries, mining often depends on the presence of regional agreements among countries, in order to ensure the free flow of movement of ore to ports and other transportation routes.

Moreover, the countries comprising our regions share more than just geological characteristics of importance to executives. That is, as regional groups they also tend to be similar in the many institutional, legal, economic and political factors that may affect location decisons. A good example is Latin America. During the 1970s mining in the countries making up these regions were characterized by strong state control of the industry, making it virtually impossible for foreign firms to gain access to reserves. However, beginning in the mid to late 1980 s, the countries of these regions began to fully liberalize their mining laws and implemen deregulation in a wide range of areas impacting on the minding industry, including land rights and mineral rights, taxation, environment protection in a bid to attract foreign mining investors. Although a very crude grouping and less meaningful than regional based groupings, separating out the very richest countries in our sample from all the rest as we have done in 2 country grouping, reflects the awareness among executives of the many different risks that are potentially involved (e.g. poor infrastructure) in setting up operations 
in countries that have fewer resources.

In addition, some countries, while fitting other regional groups, have always been viewed as unique from the point of view of the gold mining industry: Australia, South Africa, Canada, and the USA have a well-established mining presence, large reserves, and highly sophisticated production systems. New Zealand, while not containing the vast reserves that these countries posses, nonetheless has an established presence in the mining industry and shares many of characteristics of importance to the mining industry with these countries, including sophisticated technologies and similar business, infrastructural and institutional features. $^{2}$ Together the members of this group account for the majority of the output of the world's gold, and producers within these countries are also big players overseas (e.g. Goldcorp in South Africa).

A list of the countries comprising our 11country groupings is available in Appendix A. Our 8 and 2 country groupings simply modify these groups in the ways indicated above.

\subsubsection{Explanatory Variables}

We include many explanatory variables found in other studies to be associated with plant location decisions: labour costs, market size and accessibility, tax rates, market openness. In addition, we include variables designed to capture aspects of the political stability and degree of corruption of each country. As discussed in the introduction, the latter conditions have been identified as being important in respect to the increasing risks, public expectations, and competition the global mining industry faces. We also include variables that proxy the environmental regulatory costs that firms face in each country. Finally, we also include a mining industry specific "risk" variable, which rates each country on a wide range of risk factors affecting mining. With a few exceptions (see below) data are observed for 1975 to 2013. For the few mines (25) whose opening is in the future, we assign values for these variables based on the year in which the decision was made to set up the mine.

Since our explanatory variables are based on groups of countries rather than individual countries, we take the average value of all the countries in our groups to obtain an aggregate measure. We would argue that this is a reasonable strategy given that no country within each group differs widely in respect to the characteristics of interest that we measure. Data are derived from a variety of official and private sources, as specified below:

a) Investment. Unlike manufacturing and other industries, mining is an extractive activity largely carried out in enclaves and for export rather than domestic markets. Hence rather than measure domestic market size, we measure the average \% of each group's exports comprised of non-ferrous mineral ores. Data for this variable (OREEXP) was derived from the WTO's International

\footnotetext{
${ }^{2}$ Some might object to including New Zealand in this category, but we would argue that it is more similar to this group in all but the size of its reserves. However, we should also note that only 1 mine in our sample is located in New Zealand.
} 
Trade Statistics (WTO 2007). It is a measure of the average of non-ferrous metal mining production in each country group.

We also include two variables designed to measure the average openness of the group to foreign investment and trade: a) average investment share of real GDP per capita (INVEST) and average percentage of GDP in total trade (OPEN). Both variables are from Summers et al. (2006) and are measured in constant 1996 prices. The first variable was obtained by dividing investment share by real GDP plus exports minus imports. The latter variable was measured as exports plus imports divided by real GDP per capita in constant 1996 US prices. Although we do not have sufficient time series data on labour costs for all our country groups, we do have data on the productivity of labour. This is a good proxy for average relative labour costs for each group, and an important variable in its own right for mining firms, which depend on skilled labour. This variable (GDPPERW) was derived from a census definition of economically active population as reported by the International Labour Organization. It was created by dividing average real GDP income in constant US 1996 dollar prices for each group by the percentage of each group's population defined as economically active, reported in the International Labour Organization.

b) Infrastructure. Energy costs are a potentially significant factor for firms seeking to set up gold mining operations in a country. Although we do have data on industry electricity costs since 1975, the data are very incomplete, both within and across countries. Similarly, we lack sufficient data on power shortages, which have been found in Mani et al. 1996 to be significant factors in firm location decisions of manufacturers. We also lack complete worldwide data for the periods covered in our study on road and train networks, which would also be an important infrastructural characteristics for the industry. We do, however, have nearly complete data on the $\%$ of a country's population subscribing to telephone services, which we average for each group. This is our proxy for measuring the general quality of a country group's infrastructure It is derived from Estache \& Goicoechea 2005 and is designated by the acronym PHONE.

c) Environmental Stringency. We include two measures to gauge the level of environmental stringency in a country. Most plant location studies have had to resort to treaty-based measures, such as whether a country is signatory to international treaties (e.g. Smarzynska \& Wei 2004). IGiven the dearth of comparable cross-country environmental regulatory data, we also use proxy variables. However, in contrast to others, ours measures actual environmental quality and performance rather than intentional. The first one is an index value measuring the various aspects of a country's environmental quality and performance. It is one of the only global measures of environmental quality and performance. The index is measured between 0 and 100, with 0 being the worst performance and quality and 100 the best. Environmental health and ecosystem vitality are gauged using sixteen indicators of policy relevance: Air quality, water resources, biodiversity and habitat, productive natural resources, and sustainable energy. ${ }^{3}$

${ }^{3}$ The index is also significantly correlated with different measures of good governance - in- 
The environmental performance indicator (ENVPERF) was derived from the Yale Center for Environmental Law and Policy (YCELP) and the Center for International Earth Science Information Network (CIESIN) of Columbia University (2006). Data for each indicator used in the construction the index came from a variety of sources, many of them compiled for various years in the 1990s. More information can be found in CIESIN \& YCELP (2006). For this variable we have only one observation for each country for which we took the average of the group as a whole. Although far from ideal, we stress that the data can nonetheless give us a meaningful measure of a group's environmental quality and performance, as the factors that make up the index will not qualitatively change over time.

Our other environmental stringency variable is also a proxy measure, and is observed since 1975. This is a measure of each group's $\mathrm{SO}_{2}$ production per capita as a proportion of US per capita emissions $\left(\mathrm{SO}^{2}\right)$. We express national emissions per capita as a proportion of US measures in order to counteract any environmental Kuznets curve impacts of growing emissions over time due to falling or rising real GDP. $\mathrm{SO}^{2}$ emissions. Data for this variable were derived from Stern (2005), who also provides details on its measurement and sources. Real US GDP data used to construct our measure were derived from Summers et al. 2006.

d) Political Stability. Due to their substantial capital investments, it is difficult for mining firms to disinvest from a country without incurring a huge loss. For this reason mining is more susceptible to the risks inherent in unstable countries than other industries. Accordingly, they may weigh political and social factors far more heavily than do manufacturing industries. In contrast, manufacturing industries are characterized by a high degree of footlessness. They can respond to unstable political changes that may affect their operations. Since they are relatively liquid they are also much freer to set up operations in other country at comparatively low cost. In contrast, mining companies must incur high sunk costs and thus are exposed to more risks than mobile operations. Given the long-term nature of their investments, risk also arises from unstable governments that may renege on their commitments, seek to nationalize them restrict their profits, change tax rates, etc.

In our study we have two variables measuring political conditions in each group: a) a political corruption index and b) a political stability index. The first index (CORRUPT) was derived from Transparency International's Corruption Perceptions Index (2007). It measures the perceptions of corruption based on expert poll perceptions of public sector corruption by business people and country analysts. Countries are assigned a score between 0 and 10. Zero is the highest perceived level of corruption and 10 the lowest. Our data are from 1980 onwards. We assign 1980 values to the five years preceding and three years following this period. For 1980-85 and 1988-92, we assign the average value for

cluding effective regulation, controls on corruption, adherence to the rule of law, and vigorous debate over environmental policy choices. Good governance appears to be a significant component of the variation in environmental quality and performance observed across countries. For more discussion of the index see CIESIN \& YCELP (2006). 
the period to each year due to missing data. For all years after this period we observe values yearly up until 2007 (which is assigned the 2006 value). Once again, our measure is the average value of the index for all members of each group.

Our second variable measures group political stability (POLSTAB). This variable is coded from the year of the first regime transition or first year of independence. Durability of a regime would be a particularly important measure for mining industries given the huge investments they make and the relative immobility of their enterprise. While these risks may be lower in democratic regimes (e.g. Busse \& Hefeker 2005), authoritarian regimes may provide higher returns to investors (Oneal 1994) simply because they can provide predictability and hardfast rules for a firm committed to the country over the long-term. Such firms may even seek to lobby authoritarian governments as part of a risk minimizing strategy, in a way that is not possible in democratic regimes. Data for this variable were derived from the Center for International Development and Conflict Management's Polity IV project (CIDCM 2007).

e) Mining Risk Variable. This variable (MRISK) measures risk factors of particular importance to the mining industry. Each country in the group for which an average value was calculated was measured in respect to a wide range of factors that can affect the potential profitability of and stability of mining operations: a) security of tenure, aspects of mining legislation, including foreign exploration and mining companies' rights and operations, availability and accessibility of geological information and data; legislation affecting mining and exploration such as landowner's rights and access to land, mining taxation and special investments for exploration and mining; environmental regulations, particularly the degree of stringency imposed on mining companies; the general government attitude towards mining and exploration, including legal regulations and their application; country track record in exploration and mining; and the status of mining related infrastructure. Other more general factors measured in this index relate to economic and business issues applicable to all firms operating in a country (e.g. equity restrictions, controls, economic policy, payment delays, etc.). The data were derived by the Political Risk Services (PRS 2001). We have data for 1994 and 2000. For all years up to and including 1994 we assign countries the 1994 value and for all years afterwards, the value for 2000 . The higher the number the less risky the country group is deemed to be for mining investment.

f) Location of Head Office. This variable (LOHO) measures the regional (and other characteristics, including income proximity) of a new mine to its head office. Since we group countries according to different groupings, proximity here is measured in terms of whether the head office is also located in that group. Thus, if a mine was observed to open in the same country group as the head office it was accorded a 1 and 0 otherwise. ${ }^{4}$

\footnotetext{
${ }^{4}$ Recent literature suggests that other considerations may affect firm decisions. Brainard (1997), for example, argues that maximizing proximity to customers and the need to achieve economies of scale are two important cost considerations that firms will also weigh when making decisions about where to locate. Unfortunately, we do not have sufficient data to
} 


\section{Empirical Results}

In order to investigate the robustness of our results, we do not seek to come up with one "correct" specification. Rather we present results using both conditional logit and mixed logit models. Furthermore, we consider various combinations of the explanatory variables. In an appendix, we also exam the robustness of our results to changing definitions of our country groups. Our motivation for this strategy is that an empirical result which is found using several different modelling strategies is more believable than one which is found with just one. In this data set, where many of the explanatory variables are correlated with one another, an explanatory which is found to be "significant" when included with one set of explanatory variables, might be found "insignificant" with another set. Thus, presenting results for just one choice of explanatory variables could be very misleading.

\subsection{Conditional Logit Results}

Table 1 contains a benchmark set of conditional logit results ${ }^{5}$. All our models contain dummy explanatory variables for each location choice (but for the sake of brevity we do not present coefficient estimates). In initial experimentation with this data set, we also included a dummy variable for opening year. However, these were never significant in any of the regressions. Hence we only discuss time effects briefly at the end of this section.

For the reader unfamiliar with these models, note that a positive (negative) coefficient on an explanatory variable means that the higher the value of the explanatory variable, the more (less) likely the location will be chosen. The first column of Table 1 is different from the others in that it contains the results for 12 different conditional models, each containing a single explanatory variable. For instance, the first row of this column contains the estimate of the coefficient on POPDEN in a model which contains only POPDEN (and the dummy

measure these location concentration trade-offs in our data set. Even if available, they would be difficult to measure in a study with as many location alternatives as ours. For instance, the nature of our location decision study would require, as an example, that we get data on "how close Mine X was to a highway or a port". But, for every other country, we would have to have a value for this variable; that is, we would also have to know: "How close would Mine $\mathrm{X}$ have been to a highway if it were located in Australia", "How close would Mine X have been to a highway if in South Africa", and so forth. Some of this effect will be captured by the infrastructure measure (\% of phone subscribers). Moreover, the market in gold is clearly an international one and will not be affected by local or even country demand conditions.

Finally, we would argue that these considerations will be far less important in the location decisions of gold mining firms than, say, manufacturing industries, which by their very nature are far more "footlose". While they have a fair amount of choice as to where to locate a mine around the world, the number of site locations within these countries will be very small. Bound as they are by the distribution of geological ore within the country, firms will have little if any choice to concentrate production around but one or several sites at most within a country. Thus, they must focus on achieving economies of scale in these locations (e.g. through the use of larger and larger equipment) rather than trading off such achievement against proximity to customers.

${ }^{5}$ These are maximum likelihood estimates produced using Stata. 
variable for each location choice), the second row contains the estimate of the coefficient on OPEN in a model which contains only OPEN (and the dummy variable for each location choice), etc. All other columns represent a single conditional logit model with the indicated set of explanatory variables. Column 2 is perhaps the most interesting as it contains results from a regression of all the study's explanatory variables. The other columns provide representative regression results indicative of the general patterns found throughout the study, with a particular focus on the political and environmental variables.

***Insert Table 1 Here***

Looking at Table 1, we find that most of the key results are robust across different choices of explanatory variables. The strongest results are for the location of home office variable (LOHO). It is strongly significantly positive in all regressions run. This is as expected: A firm is more likely to set up a mine in the same group as its home office is located. Mining risk (MRISK) is also positive and highly significant as it was in almost every regression run. This is also as expected (recall that this variable has higher values implying less mining risk). Similarly, the estimated coefficients on political stability (POLSTAB) were positive in all regressions, but were not always significant. This is sensible in that the more stable the government on average, the more likely a firm is to set up a gold mine there. A similar result holds for the trade openness variable (OPEN). Its coefficient was consistently positive, indicating that firms are attracted to groups of countries which have more open trade, but it was significant in only the regression including all variables. The variable measuring corruption (CORRUPT) was consistently insignificant (although its point estimate was always negative, suggesting that the more corrupt countries are on average the less likely a firm will want to go there). Evidence for an influence of population density (POPDEN) in firm location decisions was found to be highly inconsistent; in some regressions it was negatively significant while in others it was positively significant. GDP per worker (GDPPERW) also showed inconsistency in its sign and significance. It was negative and significant on its own but insignificant and of the intuitively correct positive sign when included in regressions with all other variables; however, in other regressions (not reported here) excluding various variables it was positive. The study's infrastructural variable (PHONE) and the ore exports variable (OREEXP), were negative in regressions on their own as well as highly significant. In regressions with all other variables, PHONE was negative but less significant while OREXP was no longer significant and positive.

The two variables of particular interest in the study, environmental performance (ENVPER) and $\mathrm{SO}^{2}$ emissions $\left(\mathrm{SO}^{2}\right)$, provide conflicting results. The ENVPERF variable had a consistently negative sign and in many cases was significant in regressions run. Although not as consistently strong as the mining risk variable, it was moderately strong in significance in many regressions runs, implying that after other characteristics of the country groups were controlled 
for the weaker a group's environmental quality and performance (higher numbers of this variable imply a cleaner environment), the more likely firms will set up in the countries making up the group. On the other hand, the other study's proxy variable for environmental performance and health, $\mathrm{SO}^{2}$ emissions, was often strongly significant and negative, implying the complete opposite: the worse the average environmental quality of countries making up a group, the less likely firms are to set up operations in them

As noted, we also ran regressions for two other sets of country choices: 2 country groupings and 8 country groupings. Recall that the latter grouping combines Southeast Asia, East Asia and Oceania (excluding Australia and New Zealand). As Table 3 in Appendix B indicates, results are not very different from those in Table 1 for the 11 country grouping. These findings suggest that our original results are robust to changes in country groups.

Similar findings also obtained when we reduced the country groups to only two, "developed" (i.e. the world's leading mining countries and Western Europe) and developing (or all the rest of the countries in our sample). Results were qualitatively no different for the 8 and 11 groups with two exceptions in the conditional regressions including all variables. The only variable that was significant in the regression including all variables was the location of home office variable (LOHO). Moreover, in light of the results of previous analyses, it is also interesting to note that the environmental performance variable (ENVPERF) was significantly positive rather than negative as before but it was not significant. Given the coarseness of this grouping, it is probably not worthwhile attaching too much importance to these results. However, we note them here as further evidence that our 11 country groups are generally robust across the choice of meaningful country groups in all regression runs.

Finally, we also carried out conditional regression analysis of all the 11 country group dummy variables (i.e. dummy variables for each alternative) plus the year of opening of each mine times all the dummies. We did this to pick up any unobserved factors which may be related to the period in which the firm made the decision to open a mine among the set of 11 country groups. Results are not presented here for the sake of brevity (but are available on request). We note that results are less significant than previous results for the 11 country groups, due to the greater number of country coefficients to estimate. However, it is worthwhile stressing that results of our 11 country groupings also remained robust to the inclusion of opening year (interacted with dummies) and that not much more stands out to report for this part of the analysis.

\subsection{Mixed Logit Results}

This section reports results from the mixed logit analysis. Table 2 presents results for the same sets of explanatory variables as Table 1. As discussed in Train (2003, Chapter 12) mixed logit models tend to be difficult to estimate since they are parameter-rich. For this reason, coefficient estimates tend to be less precise. Nevertheless, from a purely statistical point of view, the mixed logit model is strongly favored. With noninformative priors, Bayes factors (the 
standard method of Bayesian model comparison) run into Bartlett's paradox and should not be used. However, information criteria can be given a Bayesian interpretation and can be used for model selection. Since the log-likelihood for any of our mixed logit models is several hundred higher than the corresponding conditional logit model (i.e. the model with the same set of explanatory variables), all of the standard information criteria select the mixed logit model.

At a very general level, mixed logit results are similar to conditional logit results (although coefficients are less precisely estimated with mixed logit which leads to some loss of robustness of results). However, Table 2 and Table 1 differ in a few aspects that are worth noting. First, the coefficient on our environmental performance variable is now consistently positive and significant in nearly every regression reported (as it was in every regression we ran). Hence, the mixed logit model yields results that are quite different from the conditional logit model in respect to this key variable. This result now accords with that of the $\mathrm{SO}^{2}$ emissions variable in the conditional logit analysis. Moreover, as in the latter analysis, the $\mathrm{SO}^{2}$ variable retains its negative sign in regressions including other variables and is significant in the regression including all variables (as it was in virtually every regression run). The ore export variable (OREEXP) is now highly significant and positive, indicating that countries with higher levels of ore export, the study's proxy variable measuring the degree to which mining is an established economic activity in a country, are more likely to attract new mines.

One of our key research questions is: "Do mining firms choose to open mines in countries with poor environmental records and regulations in order to avoid the costs associated with pollution management?". Our empirical results do not provide us with a totally clear, unambiguous answer to this question. But, overall, we would argue that our empirical evidence indicates that the answer to this question is "no". The coefficients on most of our environmental explanatory variables indicate that firms, if anything, choose to open in countries which (ceteris paribus) have good environmental records. The main evidence against this argument is found for the environmental performance variable in Table 1, but this result is over-turned when we use the mixed logit model.

Findings for all other variables are qualitatively the same as in the conditional logit analysis. In particular, results for the regression including all variables indicated that the coefficient for group political stability (POLSTAB) remains positive and significant, as it was in virtually every regression run. Once again, country group's population density (POPDEN) and proportion of its population owning a phone (PHONE) on are negative and significant, suggesting that country groups with high levels of these characteristics do not significantly affect firm decisions about where to locate. These findings were consistent throughout the regression analysis for results not reported here. Similarly, in the regression with all variables, the group investment variable (INVEST) was negatively significant as in the conditional logit analysis. The exception to this finding is the regression including all variables, where it was both positive and significant. The consistently negative and weakly significant finding for this variable was also repeated in regressions with other variable combinations. Mixed 
logit results indicated that groups of countries with high levels of foreign investment on average are slightly less likely to attract foreign mining firms. However, the openness to trade variable was a stronger factor in the mixed logit analysis, as was evidenced by its positive and significant coefficient in the regression with all variables (and other regression runs not reported). The worker productivity variable (GDPERW) also showed more consistency of result than in conditional logit model. It was both positive and highly significant in the regression including all variables (a pattern that repeated itself throughout the regression runs).

\section{Discussion \& Conclusion}

This paper has used both a conditional logit and a mixed logit regression approach to empirically analyze the location decisions of the world's major gold mining firms. It used a panel data set of political, economic, regulatory and financial variables observed for a large number of gold producing countries since 1975. The aim of the study was to determine the significance of environmental stringency in forming firm location decisions while controlling for other potentially important variables that may affect such decisions. Using the birth of new mines as its dependent variable, the study found mostly consistent and robust location country characteristic preferences among multinational gold mining firms. These findings paint an interesting picture of an industry that has strong preferences for countries that are not only close to home, politically stable, open to trade and productive, but also provide for low levels of financial risk and high levels of stability and predictability in mining operations. They also appear to prefer countries with clean environments, ceteris paribus, but this evidence was not as uniformly robust as these other characteristics.

Specifically, taking into account both conditional logit and mixed logit results for all our different country groupings, we found consistently strong and positive evidence for proximity of home office in affecting location decisions: Countries which saw the birth of new mines were also significantly likely to be in countries closest to where the mine's head office was located (or shared their income levels - and in the case of the big producer group including South Africa, USA , Australia, New Zealand and Canada - were established gold mining producers). They were also significantly likely to be countries with high worker productivity, and high levels of political stability. Moreover, they were also countries that provided low levels of risk in respect to factors of importance to the mining industry (e.g. security of tenure, low taxes, repatriation of profits, and so on).

Interestingly, mining firms do not appear to be attracted to countries with high population densities or with large amounts of foreign investment but a country's openness to trade appears to be an important factor. Firm's location decision does not depend, in other words, on the presence of other foreign investors in other industries, including resource (e.g. fisheries and forestry). Similarly, the quality of a country's infrastructure does not appear to be a positive drawing factor for mining firms. However, the presence of an established 
and large mining industry in the country is. These negative findings may reflect the largely enclave nature of the gold mining industry. In the case of population density, this may negative finding may also reflect the fact that environmental impacts (and thus potential costs faced by the firm) will be greater in heavily populated areas or may simply reflect the high cost of land in these areas (Mani et al. 1996).

Moreover, infrastructural requirements for the gold mining industry may be best described by the study's phone variable. Indeed, it may be that, for many gold mining firms (which typically provide their own roads and associated infrastructure), having a good infrastructure, especially telecommunications, is associated with country characteristics that are not as important as they are for industries such as manufacturing and services. While firms prefer to stay away from corrupt countries, corruption appears to be far less important than politically stability, efficiency and transparency in laws, favourable tax policies, and so on. Perhaps this is because even the risks of corruption can be minimized if the "rules of the game are known". Hence firms may treat it as simply another "cost of doing business".

In summary: Our results suggest that gold mining firms seek security, consistency and stability both from a business and a political point of view, and prefer to stay close to home. Their preference for environmentally clean and non-corrupt areas, while not as consistently strong, may itself reflect an underlying desire for the characteristics associated with good governance (Mani et al. 1996). It may also reflect the adoption of a deliberate risk management strategy by firms. That is, it is possible that the multinational gold mining firm may actually view their presence in dirty corrupt countries as a bad thing for their public image, ultimately damaging to their profit margins, despite any short-term cost savings from lower environmental standards. Such a desire becomes more understandable in light of the increasingly globalized environment in which mining firms have had to operate in the last two decades, one characterized by ever growing public and governmental expectations of corporate performance and social responsibility. Or it could simply be that environmental costs really are not paramount factors in mining firms' location decisions, because they adopt uniformly best practice standards anyway, irrespective of their location. This may itself be another risk minimization strategy aimed at inoculating themselves against possibly burdensome financial losses in years to come, as regulations in the host country become more stringent. Such strategies make rational sense given their hugely expensive and immobile investments. 


\begin{tabular}{|c|c|c|c|c|c|c|c|c|c|c|c|c|c|c|}
\hline & 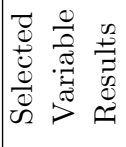 & 1 & 1 & 1 & 1 & 1 & 1 & 1 & 1 & 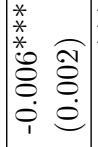 & 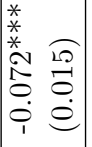 & 1 & 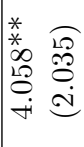 & \\
\hline & 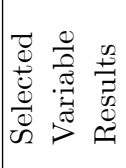 & 1 & 1 & 1 & 1 & 1 & 1 & 1 & 1 & 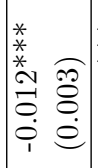 & 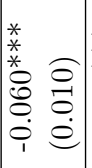 & 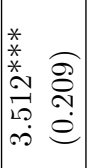 & 1 & \\
\hline & 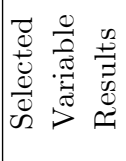 & 1 & 1 & 1 & 1 & 1 & 1 & 1 & 1 & 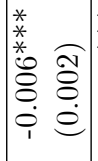 & 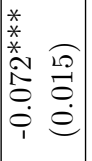 & 1 & 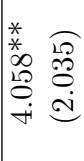 & 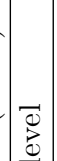 \\
\hline & 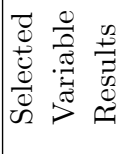 & $\begin{array}{ll}20 & 0 \\
8 & 0 \\
0 & 0 \\
0 & \dot{0} \\
1 & 0\end{array}$ & 1 & 1 & 1 & 1 & 1 & $\begin{array}{ll}\overparen{f} \\
\stackrel{0}{0} \\
0 \\
0 & 0 \\
0 & 0\end{array}$ & 1 & 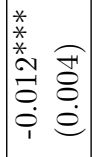 & 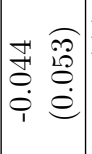 & 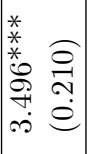 & 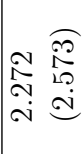 & 芜 \\
\hline & 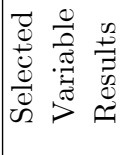 & 1 & 1 & 1 & 1 & 1 & 1 & 1 & 1 & 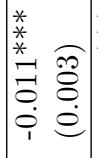 & 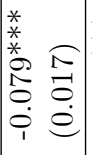 & 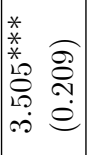 & 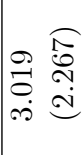 & $\mid \begin{array}{c}* \\
* \\
\dot{0} \\
\overrightarrow{0} \\
0 \\
0 \\
0\end{array}$ \\
\hline & 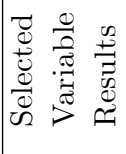 & 1 & 1 & 1 & 1 & 1 & 1 & 1 & 1 & 1 & $\mid \begin{array}{ll}* & 0 \\
0 & 0 \\
0 & 0 \\
0 & 0 \\
\dot{\varphi} & 0 \\
1 & \end{array}$ & 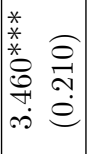 & 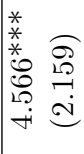 & 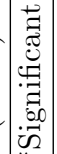 \\
\hline & 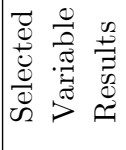 & $\begin{array}{ll}* & \widehat{8} \\
10 & 8 \\
0 & 0 \\
0 & \dot{0}\end{array}$ & 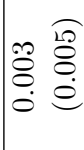 & 1 & 1 & 1 & 1 & 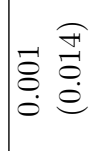 & 1 & 1 & 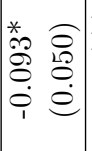 & 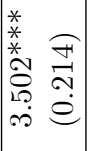 & 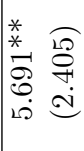 & 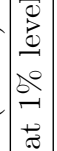 \\
\hline & 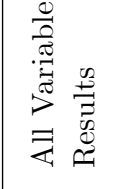 & $\begin{array}{ll}* & \widehat{2} \\
\stackrel{2}{0} & \stackrel{0}{0} \\
0 & 0 \\
0 & 0 \\
1 & 0\end{array}$ & $\begin{array}{ll}* & \widehat{\hat{S}} \\
\vec{*} & 8 \\
0 & 0 \\
0 & 0\end{array}$ & 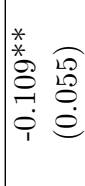 & 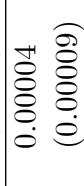 & 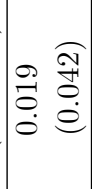 & 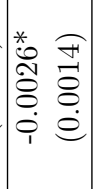 & 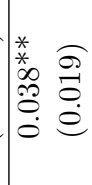 & $\mid \begin{array}{ll}-1 & 0 \\
0 & 0 \\
0 & 0 \\
0 & 0 \\
0 & 0 \\
i & 0\end{array}$ & $\mid \begin{array}{ll}0 & 0 \\
0 & 0 \\
0 & 0 \\
i & 0 \\
1 & 0\end{array}$ & 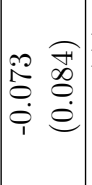 & 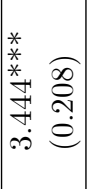 & 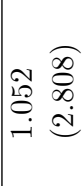 & 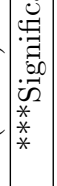 \\
\hline 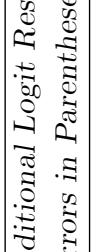 & 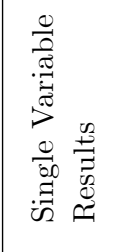 & 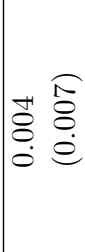 & 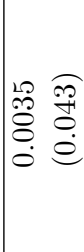 & 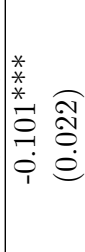 & 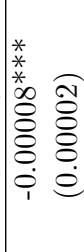 & 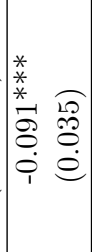 & 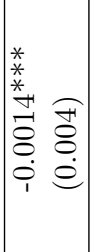 & 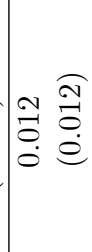 & $\begin{array}{ll}\overrightarrow{0} & \widehat{\overrightarrow{8}} \\
\dot{8} & 0 \\
0 & 0 \\
i & \dot{\theta}\end{array}$ & 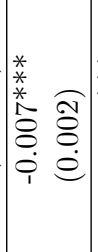 & $\left|\begin{array}{ll}* & \\
* & \\
* & 0 \\
\infty & \infty \\
0 & 8 \\
0 & 0 \\
0 & 0 \\
1 & 0\end{array}\right|$ & 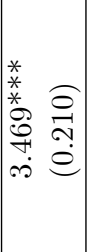 & 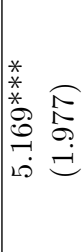 & \\
\hline 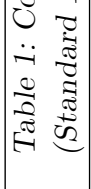 & 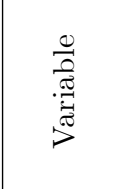 & $\begin{array}{l}\text { 公 } \\
\text { 党 } \\
0 \\
0 \\
0\end{array}$ & $\begin{array}{l}\text { 兊 } \\
\text { 至 } \\
0\end{array}$ & 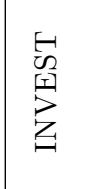 & 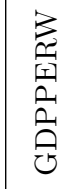 & 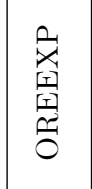 & 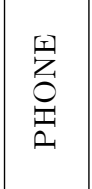 & 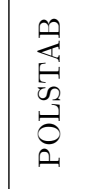 & 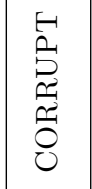 & ָo & $\begin{array}{l}\frac{1}{c} \\
\text { 空 } \\
\text { 省 } \\
\end{array}$ & 怘 & 焉 & \\
\hline
\end{tabular}




\begin{tabular}{|c|c|c|c|c|c|c|c|c|c|c|c|c|c|c|}
\hline & 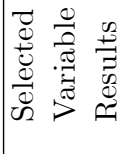 & I & I & 1 & 1 & 1 & 1 & 1 & 1 & $\begin{array}{ll}+ & 0 \\
0 & 0 \\
0 & 0 \\
0 & 0 \\
0 & 0 \\
1 & 0\end{array}$ & 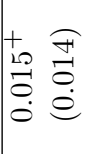 & 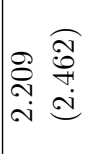 & 1 & \\
\hline & 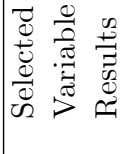 & 1 & 1 & 1 & 1 & I & 1 & 1 & 1 & $\begin{array}{cc} & 0 \\
2 & 0 \\
0 & 0 \\
0 & \dot{\theta}\end{array}$ & 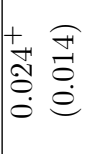 & & 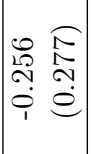 & \\
\hline & 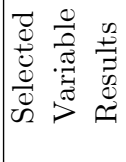 & 1 & 1 & 1 & 1 & 1 & 1 & 1 & 1 & 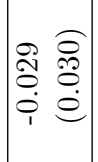 & & 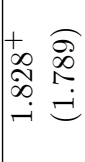 & 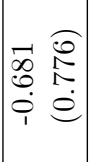 & \\
\hline & 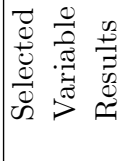 & 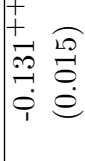 & 1 & 1 & 1 & 1 & 1 & \begin{tabular}{|ll}
+ & $\widehat{T}$ \\
0 & 0 \\
0 & 0 \\
0 & 0 \\
0 & 0
\end{tabular} & 1 & $\begin{array}{ll} & 0 \\
0 & 0 \\
0 & 0 \\
0 & 0 \\
0 & 0 \\
1 & 0\end{array}$ & 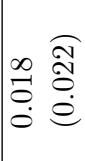 & 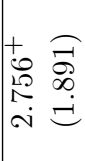 & 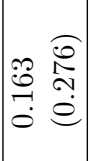 & \\
\hline & 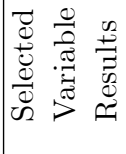 & I & 1 & 1 & 1 & I & 1 & 1 & 1 & 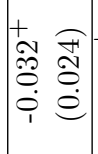 & $\mid \begin{array}{ll}+ & 0 \\
-1 & 0 \\
0 & 0 \\
0 & 0 \\
0 & 0\end{array}$ & 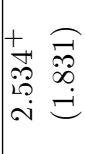 & 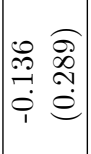 & \\
\hline & 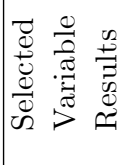 & 1 & 1 & 1 & 1 & 1 & 1 & 1 & 1 & & $\begin{array}{ll}+ & \\
+ & \widehat{\partial} \\
\stackrel{9}{P} & 0 \\
0 & 0 \\
\dot{0} & 0\end{array}$ & 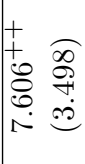 & 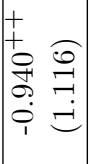 & 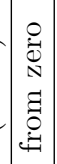 \\
\hline & 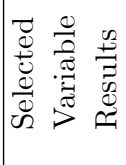 & \begin{tabular}{ll}
+ & \\
+ & 0 \\
\multirow{N}{*}{} & 0 \\
$i$ & 0 \\
$\overrightarrow{0}$ & 0 \\
1 & 0
\end{tabular} & 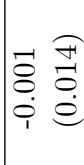 & 1 & 1 & 1 & 1 & 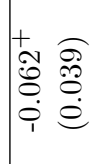 & 1 & 1 & 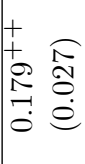 & 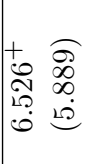 & 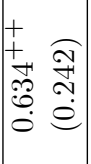 & 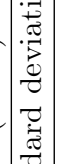 \\
\hline 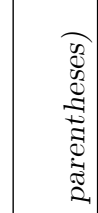 & 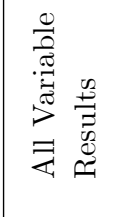 & 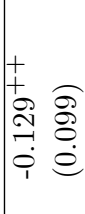 & $\begin{array}{ll}+ & \\
+ & \widehat{N} \\
20 & 8 \\
0 & 0 \\
0 & 0\end{array}$ & 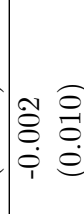 & 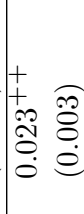 & 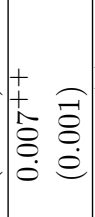 & \begin{tabular}{ll}
+ & \\
+ & 0 \\
0 & 0 \\
9 & 0 \\
\hdashline & 0 \\
0 & 0 \\
1 & 0
\end{tabular} & $\begin{array}{ll}+ & 0 \\
+ & 0 \\
0 & 0 \\
0 & 0 \\
0 & 0\end{array}$ & $\begin{array}{ll}\Re & \widehat{\sigma} \\
\stackrel{2}{0} & 0 \\
\dot{0} & \stackrel{0}{0}\end{array}$ & 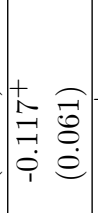 & 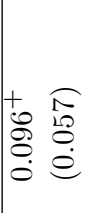 & $\begin{array}{ll}+ & \widehat{2} \\
0 & 0 \\
0 & 0 \\
0 & 0 \\
0 & 0\end{array}$ & 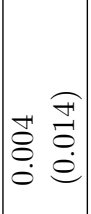 & $\mid \begin{array}{c}0 \\
\vdots \\
0 \\
11 \\
+ \\
+ \\
0 \\
0 \\
0 \\
0\end{array}$ \\
\hline 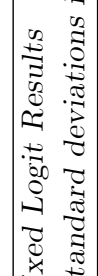 & 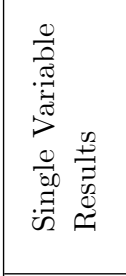 & 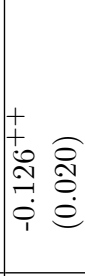 & 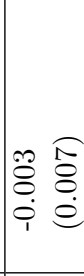 & $\mid$\begin{tabular}{ll}
+ & $\infty$ \\
\multirow{N}{N}{} & 0 \\
0 & 0 \\
0 & 0
\end{tabular} & 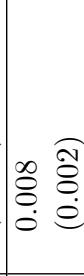 & 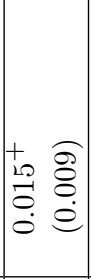 & $\mid \begin{array}{ll}\infty & \widehat{8} \\
0 & 0 \\
0 & 0 \\
1 & 0\end{array}$ & 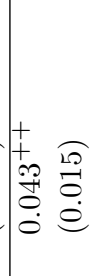 & 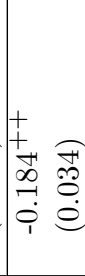 & 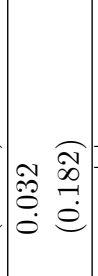 & 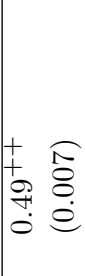 & 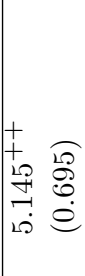 & 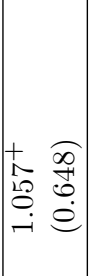 & 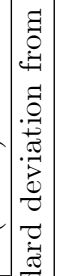 \\
\hline 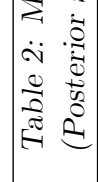 & 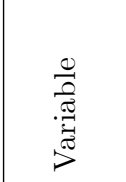 & 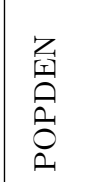 & $\begin{array}{l}\text { 辤 } \\
2 \\
0\end{array}$ & 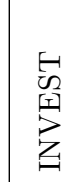 & 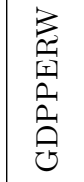 & $\begin{array}{l}\text { 希 } \\
\text { 至 } \\
\text { 究 } \\
0\end{array}$ & 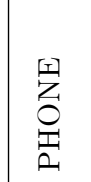 & 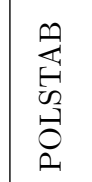 & 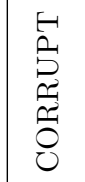 & Õ & 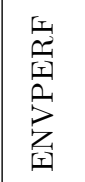 & $\stackrel{0}{0}$ & 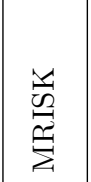 & $\begin{array}{l}\frac{\pi}{0} \\
0 \\
0 \\
0 \\
0 \\
11 \\
+ \\
+\end{array}$ \\
\hline
\end{tabular}




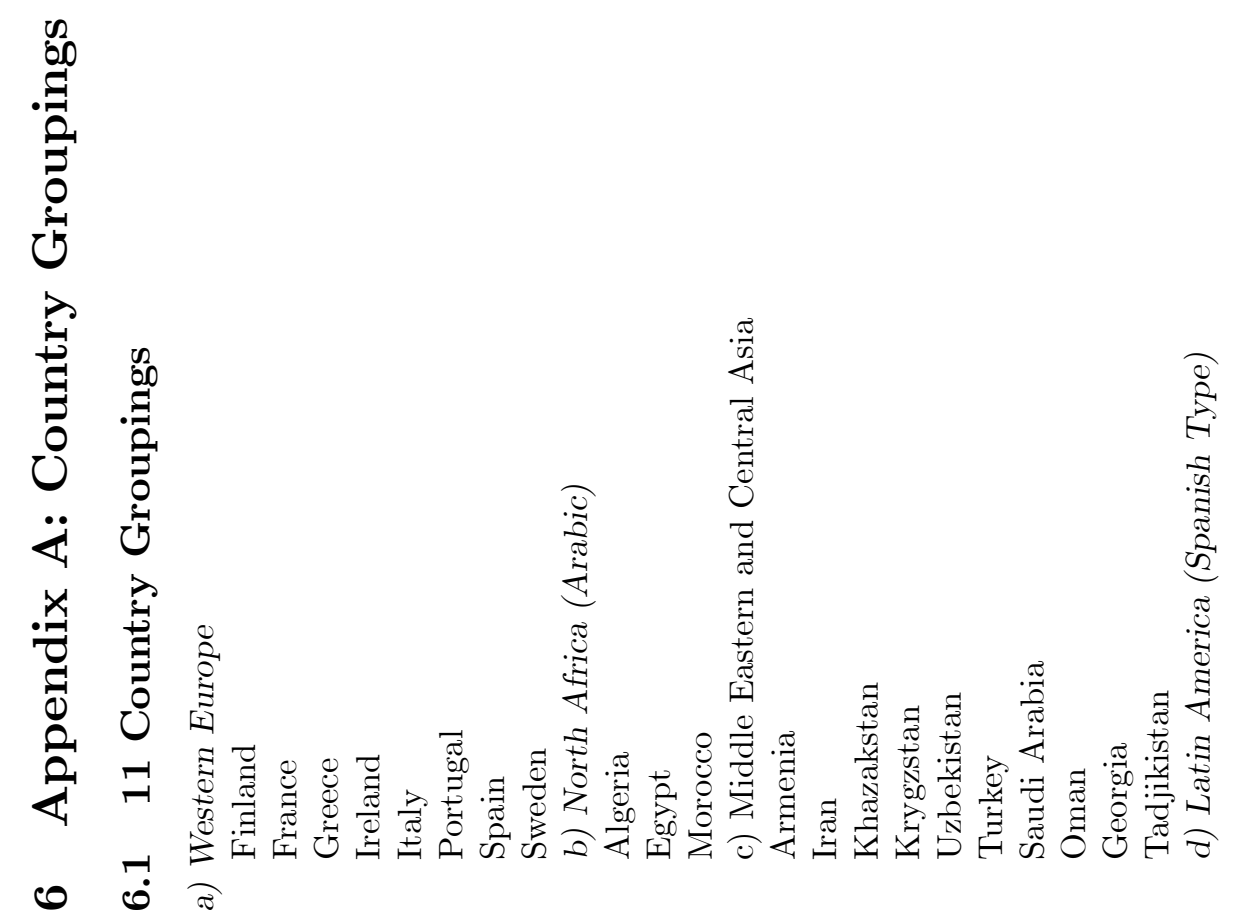




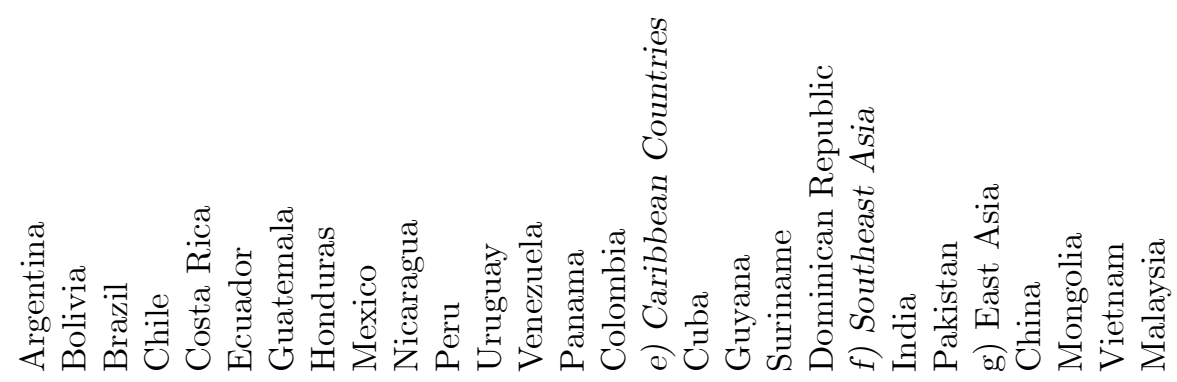




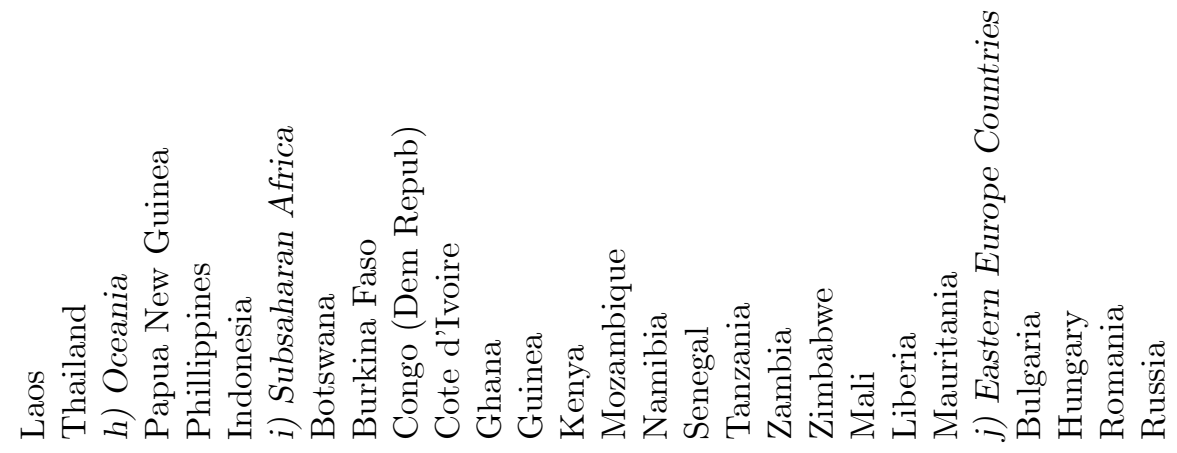




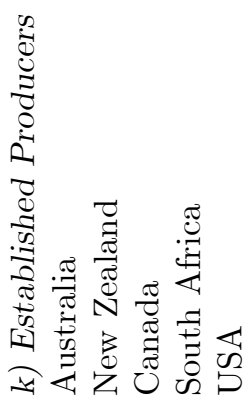




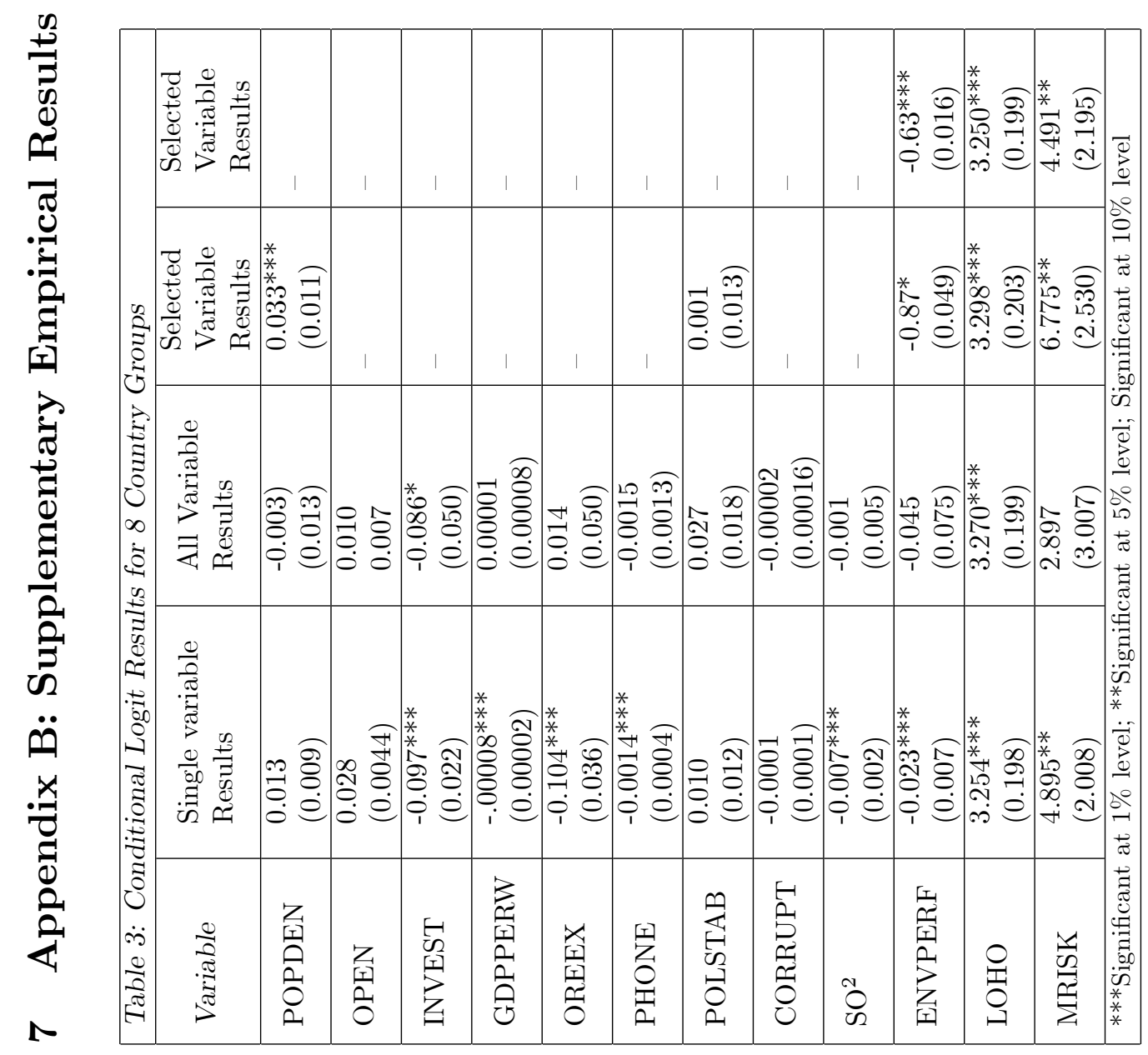




\section{References}

Barrick Gold Corporation. 2008. Global Operations: South America. http://www.barrick.com/GlobalOperations/SouthAmerica/default.aspx

Bartik, T. J. 1989. Small business Start-ups in the United States: Estimates of the Effects of Characteristics of States. Southern Economic Journal. 55(4): 1004-1018.

Baumol, W. J. and Oates, W.E. 1988. The Theory of Environmental Policy. Cambridge: Cambridge University Press.

Becker, R. and Henderson, V. 2000. Effects of Air Quality Regulations on Polluting Industries. Journal of Political Economy. 108(2): 379-421.S.

Brainard, L. 1997. An Empirical Assessment of the Proximity-Concentration Trade-Off Between Multinational Sales and Trade.

The American Economic Review. 87(4):. 520-544.

Brunnermeier, S.B. and Levinson, A. 2004. Examining the Evidence on Environmental Regulations and Industry Location. Journal of Environment and Development. 13(1): 6-41.

Busse, M. and Hefeker, C. 2005. Political Risk, Institutions, and Foreign Direct Investment. European Journal of Political Economy. 23(2): 397-415.

Center for International Development and Conflict Management 2007. Polity IV Dataset. http://www.cidcm.umd.edu/polity/

Center for International Earth Science Information Network (CIESIN) and Yale University Centre for Environmental Law and Policy..2006. Environmental Performance Index. Available at http://sedac.ciesin.columbia.edu/es/epi/index.html.

CIDCM (Center for International Development and Conflict Management). 2007. Political Regime Characteristics and Transitions, 1800 - 2004. Available at: http://www.cidcm.umd.edu/polity/.

Copeland, B, and Taylor, S. 1994. North-South Trade and the Environment. Quarterly Journal of Economics. 77(3): 765-71.

Dean, J. 2001. Overview in J.Dean (ed.). International Trade and the Environment. Ashgate Publishers.

Dean, J., Lovely, M.E. and Wang W. 2005.Are Foreign Investors Attracted to Weak Environmental Regulations?: Evaluating Evidence from China. World Bank Research Working Paper 3505.

Ederington, J., Levinson, A. and Minier, J. 2005. The Review of Economics and Statistics, MIT Press, vol. 87(1):92-99.

Estache, A. and Goicoechea, A. 2005. A Research Database on Infrastructure Economic Performance. World Bank Policy Working Paper No. 3643, June.

Eskeland, G. and Harris. A. 2003. Moving to Greener Pastures? Multinationals and the Pollution Haven Hypothesis Journal of Development Economics. 70(1): 1-23.

Heston, A., Summers, R. and Aten, B. 2006. Penn World Table Version 6.2. Center for International Comparisons of Production, Income and Prices at the University of Pennsylvania, September. 
Jaffe, A.B., Peterson, S.R., Portney, P.R. 1995. Environmental regulation and the competitiveness of US manufacturing: what does the evidence tell us?. Journal of Economic Literature 33:132-63.

Keller, W. \& Levinson, A. 2002. Pollution Abatement Costs and Foreign Direct Investment Inflows to U.S. States. The Review of Economics and Statistics. 84(4): 691-703.

Levinson, A. 1996. Environmental Regulations and Manufacturers' Location Choices: Evidence from the Census of Manufactures. Journal of Public Economics. 62(1-2): 5-29.

Levinson, A. 1999. State Taxes and Interstate Hazardous Waste Shipments. American Economic Review 89(3): 666-677.

List, J.A., Millimet, D.L. . Fredriksson, P. and McHone, W 2003. Effects of Environmental Regulations on Manufacturing Plant Births: Evidence from a Propensity Score Matching Estimator. Review of Economics and Statistics 85:4.

McConnell, V.D. and Schwab, R.M. 1990. The Impact of Environmental Regulation on Industry Location Decisions: The Motor Vehicle Industry. Land Economics 66(1): 67-81.

McFadden, D. and Train, K. 2000. Mixed MNL Models for Discrete Response. Journal of Applied Econometrics, 15(5): 447-470.

Oneal, J. R. 1994. The Affinity of Foreign Investors for Authoritarian Regimes. Political Research Quarterly 47(3): 565-588.

PRS. 2001. Political Risk Services. Risk ratings of Mining and Metal Companies in 116 countries. RMG and PRS. PRS Group Incom. Esat Syracuse NY

RMG (Raw Materials Group). 2007. Raw Materials Data. Available on CD. ET Stocholm AB, Stockholm: Sweden.

Ramy, F. 2003. Mining Reform and the World Bank: Providing a Policy Framework for Development. World Bank's Oil, Gas, Mining and Chemicals Department. World Bank and International Finance Corporation (IFC).

Rigeibeau, P.M. and Gallegos, A. 2004. Managed Trade, Liberalization and Local Pollution. Advances in Economic Analysis and Policy. 4(2): 1331-1331.

Smarzynska, B. and Wei, S-J. 2004. Pollution, Corruption and the Location of Foreign Direct Investment: Dirty Secret or Popular Myth? Contributions to Economic Analysis \& Policy 3(2).

Stern, D. 2005. Global Sulfur Emissions from 1850 to 2000. Chemosphere. 58(2): 163-175.

Train, K. 2003. Discrete Choice Methods with Simulation, Cambridge University Press, New York.

Transparency International. 2007. Corruption Perceptions Index. (CPI). Available at: http://www.transparency.org/tools/measurement.

WTO (World Trade Organization). 2007. International Trade \& Tariff Data. http://stat.wto.org/Home/WSDBHome.aspx.

Wu, X 2004. Pollution Havens and the Regulation of Multinationals with Asymmetric Information. Contributions to Economic Analysis and Policy. 3(2): $1-25$. 